\title{
Effect of obesity on the outcome of pregnancy in primigravida patients: an Iraqi experience
}

\section{Ban Dawood Mahmood*}

Department of Obstetrics and Gynecology, Ibn Albaladi Hospital, Baghdad, Iraq

Received: 17 January 2019

Accepted: 24 January 2019

\section{*Correspondence:}

Dr. Ban Dawood Mahmood,

E-mail: drbandawood@yahoo.com

Copyright: (C) the author(s), publisher and licensee Medip Academy. This is an open-access article distributed under the terms of the Creative Commons Attribution Non-Commercial License, which permits unrestricted non-commercial use, distribution, and reproduction in any medium, provided the original work is properly cited.

\begin{abstract}
Background: A parallel rise in the rate of obesity in women in reproductive age; and cesarean section as outcome of pregnancy is noticed in the last years in our society. It is unknown whether this dual rise is related or not. The impact is more evident on primigravida patients, so authors perform this study to assess the impact of obesity on the outcome of pregnancy in primigravida patients in a major obstetrics hospital.

Methods: A prospective controlled study was conducted in Ibn Al-Balady obstetrics hospital. It included 121 primigravida patients who were divided into 3 groups according to WHO BMI categories: normal, overweight, and obese. The mode of delivery of these patients is recorded and was assessed in relation to BMI.

Results: About $17 \%$ of the patients were obese and they needed more emergency CS as a mode of delivery than normal BMI patients $(\mathrm{p}<0.01)$. They also had longer second stage of labor $(\mathrm{p}<0.01)$ and delivered babies with higher birth weight that the normal group $(\mathrm{p}<0.05)$.

Conclusions: Obesity constitutes a growing challenge on the outcome of pregnancy, duration of second stage of labor and baby birth weight in primigravida patients. Women who are getting pregnant for the first time should be advised to lower their BMI as a safety measure to avoid emergency cesarean section.
\end{abstract}

Keywords: BMI, Cesarean section, Mode of delivery, Obesity, Pregnancy, Primigravida, Second stage of labor

\section{INTRODUCTION}

Obesity has considerable implications for general health and the development of diseases such as diabetes mellitus, coronary artery disease, stroke, and endometrial cancer. This increasing prevalence of obesity also constitutes a major problem in obstetric practice. It is well established that a strong association exists between obesity and the complications of pregnancy and delivery. ${ }^{1-3}$ Although these data were taken from the Western society, little data is available about the dilemma of obesity in our society. Rising national incomes and increased 'Westernization' is a major cause of increased levels of obesity in women in the developing countries. ${ }^{4}$ In Iraq, between 1997 and 2007 the prevalence of obesity among women in reproductive age increased from 23.6 to 25\%.5 The rates of Cesarean Section in Baghdad city were 17.9,19 and 28.7\% in 2007, 2009 and 2011; respectively, but the impact of obesity in this rise is not known. 6,7

Obesity is measured by body mass index (BMI) in $\mathrm{kg} / \mathrm{m}^{2}$ units. ${ }^{8}$ According to which, there are three categories: underweight (BMI $<18.5 \mathrm{~kg} / \mathrm{m}^{2}$ ), normal weight (BMI $\left.25.0-29.9 \mathrm{~kg} / \mathrm{m}^{2}\right)$ and obese $\left(\right.$ BMI $\left.>29.9 \mathrm{~kg} / \mathrm{m}^{2}\right)$. Poobalan et al concluded, in a prospective controlled study, that the risk of CS was higher for women who were first-time mothers or overweight. ${ }^{9}$ In another prospective study, obese primigravida patients were found to have a higher 
rate of labor induction and emergency CS than those with normal BMI. ${ }^{10}$

Emergency CS is a cesarean section that is performed as labor fails to progress and deliver the baby. A recent study suggested that marriage is associated with a significant weight gain which is more immediately noticeable in women. ${ }^{11}$ Our society is not an exception to the rule; therefore, the problem of obesity in primigravida patients need to be addressed seriously. Obese women were found to be 6 times more likely to have cesarean section due to cephalo-pelvic disproportion or failure to progress than non-obese women. ${ }^{12}$

The objective is to study the effects of maternal obesity (body mass index BMI >30) on the mode of delivery for primigravida patients.

\section{METHODS}

A prospective controlled study was conducted in a major obstetric hospital (Ibn al-Balady obstetrics and children hospital) that serves a major part of population in the eastern district of Baghdad. One hundred forty-one (141) patients were enrolled in this study; all of them visit the same center.

\section{Inclusion criteria}

- The criteria of inclusion comprised patients with no chronic diseases as hypertension, diabetes mellitus or other systemic diseases, patients with singleton pregnancy of $>37$ weeks, and with normal lie, cephalic presentation.

\section{Exclusion criteria}

- Multiparous patients were excluded.

Antenatal care period was observed closely recording the body weight and height at the first trimester and monitoring the condition of the fetus as in any antenatal clinic. Informed consent was obtained from all of patients. Clinical and socio-demographic details were collected for subsequent analysis. The World Health Organization BMI categorization was used, i.e. underweight (BMI $<18.5 \mathrm{~kg} / \mathrm{m}^{2}$ ), normal weight (BMI $25.0-29.9 \mathrm{~kg} / \mathrm{m}^{2}$ ) and obese $\left(\mathrm{BMI}>29.9 \mathrm{~kg} / \mathrm{m}^{2}\right.$. The BMI of each patient was obtained by dividing the weight in $\mathrm{kg}$ by the height squared in meters $\left(\mathrm{m}^{2}\right)$.

Subsequently, they were divided into three categories: normal, overweight, and obese. Morbidly obese patients were out of the scope of this study. At labor time, spontaneous vaginal delivery is initiated. Every subsequent event was recorded including the need for induction, uterine contractions and their frequency, status of the fetus, and cervical dilatation, the length of the second stage, and conversion to emergency CS. After delivery the baby's weight for each patient was recorded.

\section{Statistical analysis}

Statistical analysis was performed using Data Analysis Add-in of Excel 2013 for Windows. The differences in the variables were evaluated by t-test or by One-way ANOVA test. The results were assessed at a confidence interval of $95 \%$ and at a significance level of $p<0.05$.

\section{RESULTS}

Twenty (20) of the 141 patients were lost to follow up and did not complete the study so we are left with 121 patients. The age ranged between (19-36 years) with a mean of 25.5 years.

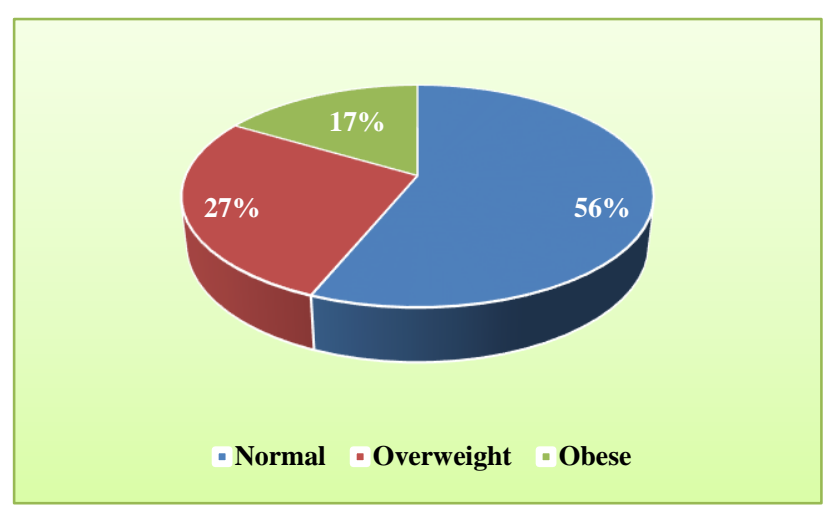

Figure 1: BMI categories (percentage) in 121 patients.

The BMIs ranged between (24.6 to 32.8) with a mean of 24.6. Of the 121 patients $68(56 \%)$ were normal, 33 (27\%) were overweight, and $20(17 \%)$ were obese (Figure 1 and 2).

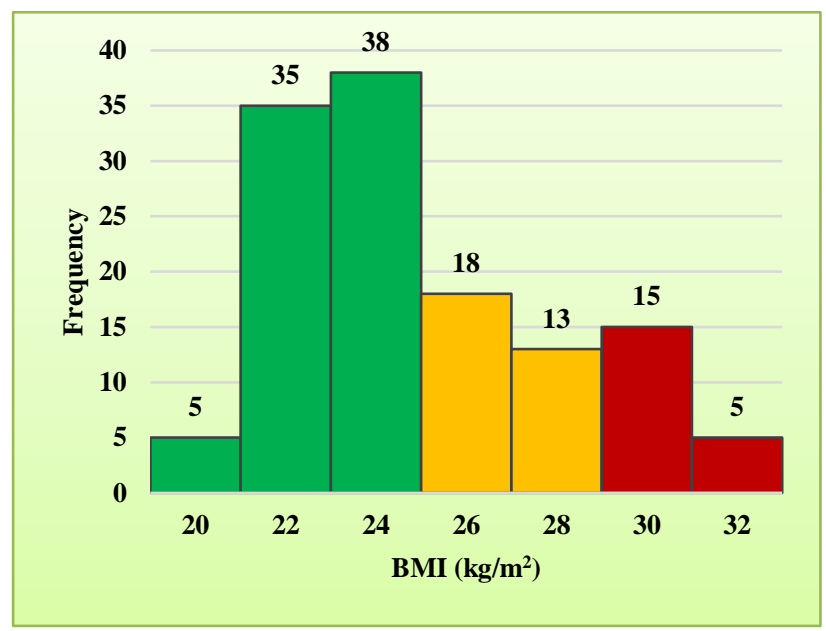

Figure 2: BMI distribution in 121 patients by number.

The mode of delivery for primigravida women for each of the three BMI categories is shown below. Eighty-two $(68 \%)$ of the patients enrolled in the study had normal vaginal delivery without induction with normal progress of labor. Most of them $(61,50 \%)$ are in the normal BMI category, $12(10 \%)$ are overweight and $2(1.6 \%)$ only are 
obese. Only five (4\%) of the normal BMI patients needed their labor to be induced, while the induced labor number was the same for overweight and obese BMI category (six). Twelve of twenty $(10 \%)$ of the obese patients had emergency CS as an outcome for their pregnancy, as well as eight of thirty-three (6\%) overweight women; and only two $(1.6 \%)$ of the normal BMI category (Table 1$)$.

Table 1: Modes of delivery for 3 BMI categories.

\begin{tabular}{|l|l|l|l|l|}
\hline & Labor with induction & Labor without induction & C/S & Total \\
\hline Normal & $5(4 \%)$ & $61(50 \%)$ & $2(2 \%)$ & $68(56 \%)$ \\
\hline Overweight & $6(5 \%)$ & $19(16 \%)$ & $8(6 \%)$ & $33(27 \%)$ \\
\hline Obese & $6(5 \%)$ & $2(2 \%)$ & $12(10 \%)$ & $20(17 \%)$ \\
\hline Total & $17(14 \%)$ & $82(68 \%)$ & $22(18 \%)$ & 121 \\
\hline
\end{tabular}

The second stage of labor in all patients was 61 minutes in average with a range of (21-117) minutes, but it had a mean of 31 minutes in normal BMI category, 60 minutes in overweight, and 100 minutes in obese patients (Figure $3)$.

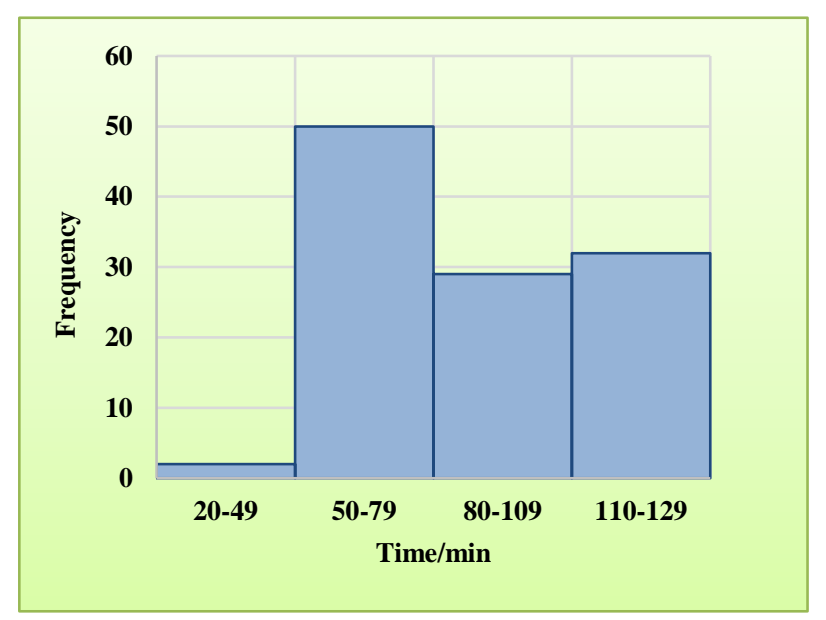

Figure 3: Length of second stage of labor.

As shown in Figure 4, almost a linear relationship is seen between the BMI of the patient and the duration of the second stage (correlation coefficient $=0.94)($ Figure 4$)$.

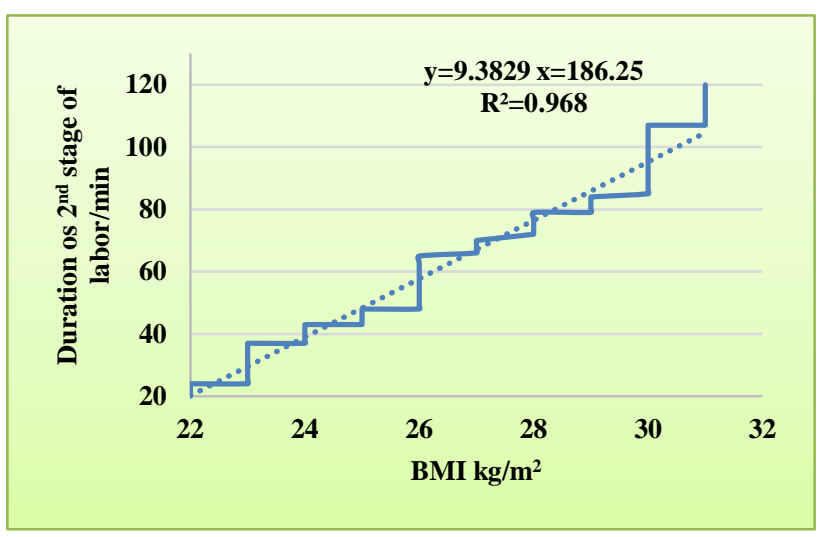

Figure 4: Relation between duration of second stage of labor and BMI of the mother.
It was shown that there was $53.71 \%$ of the new birth with weight range between $3.5-4 \mathrm{~kg}$. Another $23.96 \%$ of the newborn had weight range between $2.5-3 \mathrm{~kg}$ and the rest had birthweight of 2-2.5kg (Figure 5).

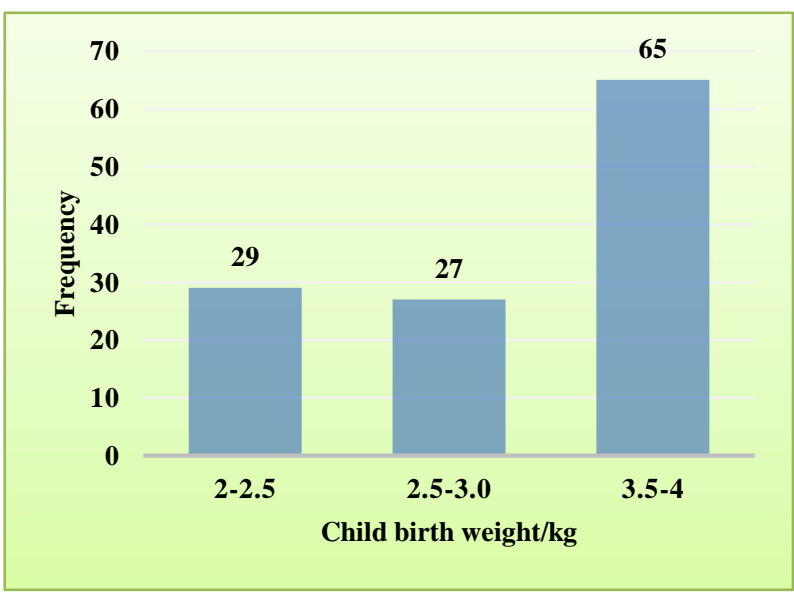

Figure 5: Child birth weight in 121 patients.

Examining the relationship between birthweight and mother's BMI showed that there is a linear relationship is seen between the BMI of the mother and the mean birthweight (correlation coefficient=0.95) (Figure 6).

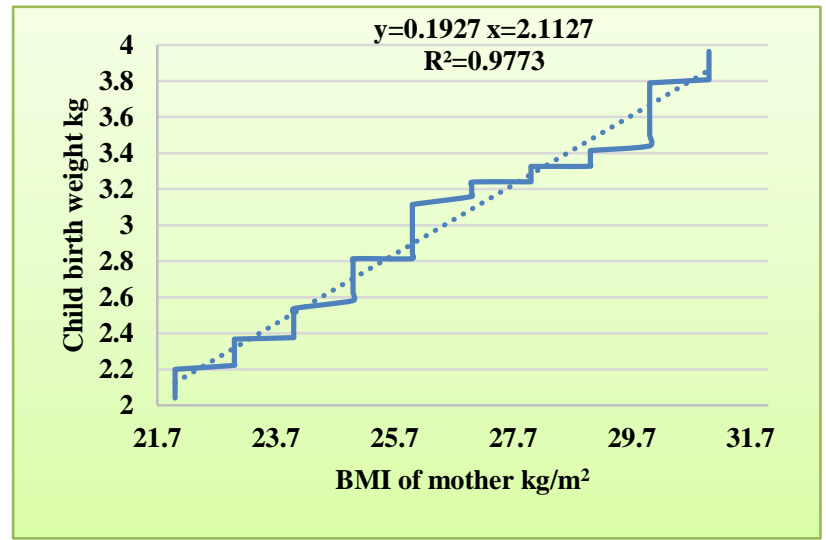

Figure 6: Child birth weight versus BMI of the mother. 
In a similar way, child birth weight was found to be higher in obese mothers with an average of $3.73 \mathrm{~kg}$, while in overweight mothers it was $3.16 \mathrm{~kg}$ and $2.73 \mathrm{~kg}$ in normal BMI category BMI, with a strong correlation coefficient of 0.97 . About $78 \%$ of the emergency CS performed was due to fetal distress, only $22 \%$ were caused by dystocia. T-test results of the outcome of pregnancy in each category are shown in Table 2.

Table 2: Comparison of outcome of pregnancy in 3 BMI categories.

\begin{tabular}{|l|l|l|}
\hline $\begin{array}{l}\text { BMI categories } \\
\text { compared }\end{array}$ & p-value & Significance \\
\hline Normal vs overweight & 0.000844913 & Yes: $\mathrm{p}<0.01$ \\
\hline Normal vs obese & $3.006 \times 10^{-9}$ & Yes: $\mathrm{p}<0.01$ \\
\hline Overweight vs obese & $8.045 \times 10^{-5}$ & Yes: $\mathrm{p}<0.01$ \\
\hline
\end{tabular}

\section{DISCUSSION}

The effect of obesity on the outcome of pregnancy has been the interest of many researchers over the last three decades for its prime importance mainly on the mother's and child's health and as a burden on obstetrics hospitals due to increasing number of cesarean sections done. ${ }^{13}$ It has been estimated that each $1 \%$ decrease in the number of obese mothers in the United States would translate into 16,000 fewer CS per annum. ${ }^{14}$

Dysfunctional active phase labor patterns have been recognized by Verdiales et al, in obese mothers as compared to lean women; mainly as arrest of dilatation leading to failure to progress, elongation of the second stage of labor and resulting in emergency CS as seen in 15 of the obese patients enrolled in present study, moreover, an increased maternal BMI is associated with the risk of caesarean section due to dystocia according to Roman et al, as seen in 5 of 20 patients with a BMI of $>30 \mathrm{~kg} / \mathrm{m}^{2} \cdot{ }^{13,15}$

The pre-pregnancy body weight is the least important factor to most of the women in our society and may be considered as a beauty privilege rather than a negative factor on the future pregnancy, but this may be overlooked by the obstetrician or the GP practitioners as these women become pregnant for the first time and show in antenatal care units, although they constitute only $17 \%$ of the primigravida patients. The outcome of the first pregnancy should be spontaneous vaginal delivery as a cesarean section may doom the woman for her life as she will not be allowed a normal vaginal delivery after the first CS. Another study found that there is a significant linear association between pre-pregnancy maternal corpulence (BMI) and risk of caesarean deliveries in pregnancies at term. ${ }^{16}$ In present study, elongation of second stage of labor and baby child weight were found to have such a linear relation with cesarean section. Table 2 summarizes the outcome of pregnancy of the three categories and clearly shows a statistically significant difference between normal and each of overweight $(p<0.05)$ and obese categories $(p<0.01)$ on one side; and between overweight and obese ones $(p<0.01)$ on the other. Obese patients have longer second stage of labor $(\mathrm{p}<0.01)$ and delivered babies with more birth weight $(\mathrm{p}<0.05)$.

\section{CONCLUSION}

More overweight and obese women are encountered in our obstetrics practice from the antenatal care to the delivery time, which constitutes a growing challenge on the outcome of pregnancy, duration of second stage of labor and baby birth weight.

\section{Recommendations}

Obese women should be advised to control their body weight before getting pregnant for the first time as this will significantly lower the rate of emergency CS.

\section{Funding: No funding sources}

Conflict of interest: None declared

Ethical approval: The study was approved by the Institutional Ethics Committee

\section{REFERENCES}

1. Weiss JL, Malone FD, Emig D, Ball RH, Nyberg DA, Comstock CH, et al. Obesity, obstetric complications and cesarean delivery rate-a population based screening study. Am J Obstet Gynecol. 2004;190: 1091-7.

2. Kabiru W, Raynor B. Obstetric outcomes associated with increase in BMI category during pregnancy. Am J Obstet Gynecol. 2004;191:928-32.

3. Sebire NJ, Jolly M, Harris JP, Wadsworth J, Joffe M, Beard RW, et al. Maternal obesity and pregnancy outcome: a study of 287,213 pregnancies in London. Int J Obes Relat Metab Disord. 2001;25:1175-82.

4. Martorell R, Khan LK, Hughes ML, GrummerStrawn LM. Obesity in women from developing countries. Europ J Clin Nutr. 2000;54(3):247-52.

5. Al-Twail NG, Abdulla NM, Abdul Ameer AJ. Prevalence of and factors associated with overweight and obesity among a group of Iraqi women. Eastern Mediter Health J. 2007;13(2):420-9.

6. Al-dobony SJ. Rate, Indications and risk factors of cesarean section in maternity hospital in Baghdad city. Iraqi Board of Medical Specialization, Community Medicine. 2009.

7. Ministry of Health: Multiple Indicator Cluster Survey Final Report, Iraq 2006 ( MICS 3), Central Organization for Statistics and Information Technology, Kurdistan Regional Office. Iraq: United Nations Children Fund; 2007.

8. Keys A, Fidanza F, Karvonen MJ, Kimura N, Taylor HL. Indices of relative weight and obesity. J Chronic Dis. 1972;25(6):329-43.

9. Poobalan AS, Aucott LS, Gurung T, Smith WCS, Bhattacharya S. Obesity as an independent risk factor 
for elective and emergency caesarean delivery in nulliparous women- systematic review and metaanalysis of cohort studies. Obes Rev. 2009;10:28-35.

10. O'dawyer V, O'Kelly S, Monaghan B, Rowan N, Farah N, Turner M. Maternal obesity and induction of labor. Acta Obstet Gynecol Scand. 2013;92:14148.

11. Shafer E. The effect of marriage on weight gain and propensity to become obese in the African American community. J Fam Issues. 2010;31:1166-82.

12. Barau G, Robillard PY, Hulsey TC, Dedecker F, Laffite A, Gérardin P, et al. Linear association between aternal body mass index and risk of cesarean section in term deliveries. BJOG. 2006;113:1173-7.

13. Verdiales M, Pacheco C, Cohen WR. The effect of maternal obesity on the course of labor. J Perinat Med. 2009;37:651-5.

14. Chu SY, Schmid CH, Dietz PM, Callaghan WM, Lau J, Curtis KM. Maternal obesity and risk of cesarean delivery: a meta-analysis. Obes Rev. 2007;8:385-94.

15. Roman H, Goffinet F, Hulsey TF, Newman R, Robillard PY, Hulsey TC. Maternal body mass index at delivery and risk of caesarean due to dystocia in low risk pregnancies. Acta Obstet Gynecol. 2008;87:163-70.

16. Barau G, Robillard PY, Hulsey TC, Dedecker F, Laffte A, Gérardin P, et al. Linear association between maternal pre-pregnancy body mass index and risk of caesarean section in term deliveries. $\mathrm{Br} \mathrm{J}$ Obstet Gynaecol. 2006;113:1173-7.

Cite this article as: Mahmood BD. Effect of obesity on the outcome of pregnancy in primigravida patients: an Iraqi experience. Int J Reprod Contracept Obstet Gynecol 2019;8:815-9. 